\title{
Intrinsic and Network Contributions to Reverberatory Activity: Reactive Clamp and Modeling Studies
}

\author{
Jean-Marc Fellous, Terrence J. Sejnowski, and Zaneta Navratilova
}

\begin{abstract}
Cortical cells belong to small interconnected ensembles. These ensembles have the potential of being activated in a reverberatory fashion in vitro and in vivo, spontaneously or in response to stimulation. We combined computer simulations and in vitro intracellular recording from prefrontal cortical neurons to explore the elicitation, modulation, and termination of these reverberations. In computer simulations, we studied the reverberating activity of small networks of neurons connected with realistic stochastic synaptic transmission and concluded that about 40 excitatory cells and a few interneurons were sufficient to reproduce the membrane and firing characteristics observed in vivo. Using a variant of the dynamic-clamp technique in vitro, we then stimulated the assembly and triggered self-sustained activity mimicking the activity recorded during the delay period of a working memory task in the behaving monkey. The onset of sustained activity depended on the number of action potentials elicited by the cue-like stimulation. Too few spikes failed to provide enough NMDA current to drive sustained reverberations; too many spikes activated a slow intrinsic hyperpolarizing current that prevented spiking; an intermediate number of spikes produced sustained activity. The firing rate during the delay period could be effectively modulated by the standard deviation of the inhibitory background synaptic noise without significant changes in the background firing rate before cue-onset. These results suggest that the balance between fast feedback inhibition and slower AMPA and NMDA feedback excitation is critical in initiating persistent activity, that intrinsic currents may determine which cell contributes to the onset or offset of reverberations and that the maintenance of persistent activity may be regulated by the amount of correlated background inhibition.
\end{abstract}

J.-M. Fellous $(\triangle)$

Department of Psychology and Program in Applied Mathematics, ARL Division of Neural Systems, Memory and Aging, University of Arizona, Tucson, AZ 85724, USA e-mail: fellous@arizona.edu 


\section{Introduction}

Groups of neurons are able to enter a state of self-sustained activity in response to stimuli. Such reverberatory activity is found in many parts of the mammalian brain including different subfields of the hippocampus (Hahn et al., 2007), in the monkey ventral premotor area (Graziano et al., 1997), and at several levels of the visual pathway and prefrontal cortices during working memory tasks (Goldman-Rakic, 1995; Pratt and Mizumori, 2001; Shadlen and Newsome, 2001; Casagrande et al., 2002; Hoffman et al., 2007). Reverberating activity also occurs spontaneously in vitro (Cossart et al., 2003). The fact that local reverberations are found both in vitro and in vivo point to a potentially essential feature of the cortex which is that neurons belong to small ensembles. Forming small ensembles of interconnected cells may increase the robustness of their co-activation (a few neurons misfiring would not affect the activity of the ensemble) and their postsynaptic impact (on a common target, an increase in near-synchronous inputs overcomes synaptic unreliability, and increases postsynaptic spatial integration). Other types of reverberatory activity can be found during sleep (natural or induced), and involve large, system-wide synchronization. These types of global up-states will not be considered here (El Boustani et al., 2007, but see Hughes et. al. "Using the Dynamic Clamp to Dissect the Properties and Mechanisms of Intrinsic Thalamic Oscillations" in this volume), although their underlying neural bases may share common features with that of local reverberations.

Optical recordings from cat cortex in vivo (Tsodyks et al., 1999) and calcium imaging from rat layer 5 neurons in vitro (Mao et al., 2001) have demonstrated that the activity of single cells can be strongly correlated with a spatial pattern of activity in neighboring neurons. This correlation results in part from local excitatory and inhibitory synaptic reverberations among groups of interconnected cells (Melchitzky et al., 1998; Gonzalez-Burgos et al., 2000; Okun and Lampl, 2008) and together with membrane currents is thought to be the basis for persistent activity observed in the prefrontal cortex during working memory tasks (Durstewitz et al., 2000; Wang, 2001). The exact nature of these reverberations and their dependence on a particular mixture of excitation and inhibition is under active investigation (McCormick et al., 2003; Hasenstaub et al., 2005; Haider et al., 2007). Neurons have a wide range of membrane currents that can potentially change the nature of their contribution to the reverberating ensemble. Intrinsic properties such as input resistance, threshold, burstiness, or spike frequency adaptation can determine the extent to which a given cell contributes to the initiation, termination, or maintenance of sustained activity, of which an 'up-state' is a special case (Luczak et al., 2007).

The goal here was to recreate the in vivo conditions of an elementary prefrontal cortical microcircuit in a computational model, and in an in vitro preparation by injecting simulated long-range synaptic background conductances and short-range excitatory and inhibitory feedback using a variant of the 
dynamic-clamp technique. We studied some of the conditions that lead to the onset and offset of sustained reverberatory activity and we investigated the contribution of background synaptic noise to the level of activity during the reverberation.

\section{Materials and Methods}

\subsection{Computer Simulations}

All simulations were performed using the NEURON simulator (Hines and Carnevale, 1997). Two types of neurons were simulated: Excitatory, pyramidallike neurons, and inhibitory gamma-amino butyric acid (GABA)ergic neurons (Navratilova and Fellous, 2008). The excitatory neurons were configured as 'ball and stick' and had a single somatic compartment, and a dendrite comprised of ten compartments. Passive leak currents adjusted to give an input resistance of $90 \mathrm{M} \Omega$, were inserted in all compartments. Voltage-gated sodium and potassium currents were added to the soma (Golomb and Amitai, 1997) and adjusted to give an action potential generation threshold of $-53 \mathrm{mV}$. To control the bursting properties of pyramidal neurons, a calcium-activated potassium channel (Destexhe et al., 1994) a calcium channel, a calcium pump, and intracellular calcium first order buffering (Destexhe et al., 1993) were added to the somatic compartment. Inhibitory neurons consisted of a single somatic compartment, and included voltage-gated sodium and potassium currents and passive leak currents adjusted to give an input resistance of $150 \mathrm{M} \Omega$.

An Ornstein-Uhlenbeck background synaptic noise source (Destexhe et al., 2001) was added to the soma of each neuron to mimic long range inputs from neurons outside of the simulated network.

Briefly,

$$
I_{\text {background }}(t)=G_{\mathrm{e}}(t)\left(V(t)-E_{\mathrm{GLU}}\right)+G_{i}(t)\left(V(t)-E_{\mathrm{GABA}}\right)
$$

where $E_{\mathrm{GLU}}$ and $E_{\mathrm{GABA}}$ are the reversal potentials for AMPA and GABA conductances ( 0 and $-80 \mathrm{mV}$, respectively) and $V$ is the instantaneous membrane voltage of the recorded pyramidal cell. The fluctuating conductances $G_{\mathrm{e}}(t)$ and $G_{\mathrm{i}}(t)$ are given by two Ornstein-Uhlenbeck processes (Uhlenbeck and Ornstein, 1930):

$$
\begin{aligned}
& \frac{\mathrm{d} G_{\mathrm{e}}(t)}{\mathrm{d} t}=-\frac{1}{\tau_{\mathrm{e}}}\left[G_{\mathrm{e}}(t)-G_{\mathrm{e} 0}\right]+\sqrt{D_{\mathrm{e}}} \chi_{1}(t) \\
& \frac{\mathrm{d} G_{\mathrm{i}}(t)}{\mathrm{d} t}=-\frac{1}{\tau_{\mathrm{i}}}\left[G_{\mathrm{i}}(t)-G_{\mathrm{i} 0}\right]+\sqrt{D_{\mathrm{i}}} \chi_{2}(t)
\end{aligned}
$$


where $G_{\mathrm{e} 0}$ and $G_{\mathrm{i} 0}$ are average conductances, $\tau_{\mathrm{e}}$ and $\tau_{\mathrm{i}}$ are time constants $(2.7$ and $10.7 \mathrm{~ms}$, respectively), $\chi_{1}(t)$ and $\chi_{2}(t)$ are Gaussian white noise processes with unit standard deviation, and $D_{\mathrm{e}}$ and $D_{\mathrm{i}}$ are the "diffusion" coefficients. $G_{\mathrm{e}}$ and $G_{\mathrm{i}}$ are Gaussian variables with standard deviations $\sigma_{\mathrm{e}}=\sqrt{D_{\mathrm{e}} \tau_{\mathrm{e}} / 2}$ and $\sigma_{\mathrm{i}}=\sqrt{D_{\mathrm{i}} \tau_{\mathrm{i}} / 2}$, respectively. These standard deviations were adjusted so that membrane potential fluctuations of the simulated neurons resembled those during a down-state in vivo $\left(G_{\mathrm{e} 0}=4 \mathrm{nS}, G_{\mathrm{i} 0}=35 \mathrm{nS}, \sigma_{\mathrm{e}}=0.95 \mathrm{nS}, \sigma_{\mathrm{i}}=3 \mathrm{nS}\right.$ for excitatory neurons, and $\sigma_{\mathrm{e}}=0.54 \mathrm{nS}, \sigma_{\mathrm{i}}=2.1 \mathrm{nS}$ for inhibitory neurons). Pyramidal neurons were connected to each other with AMPA/NMDA dynamic synapses showing facilitation and depression (Maass and Zador, 1999). These synapses were positioned onto a random dendritic compartment. There were approximately four times fewer inhibitory neurons than pyramidal neurons. Each inhibitory neuron received inputs from all the pyramidal neurons and output onto the somatic compartment of each pyramidal neuron to create shunting of the currents from the dendrite. GABAergic synapses were deterministic (Destexhe et al., 1996) and interneurons were not interconnected.

\subsection{In Vitro Experiments}

Regularly spiking layer 5 pyramidal cells from rat pre-limbic and infra-limbic areas of prefrontal cortex were recorded with the patch-clamp technique from 2 to 4 -weeks-old Sprague-Dawley rats using standard techniques (Fellous and Sejnowski, 2003).

Data were acquired using two computers, one computer for standard data acquisition, current injection, and extracellular stimulation, and a second computer dedicated to real-time synaptic current injection (Fig. 1C). Programs for data acquisition were written using Labview 6.1 (National Instrument, Austin, TX), and data were acquired with a PCI16-E1 data acquisition board (National Instrument, Austin, TX). Data acquisition rate was either 10 or $20 \mathrm{kHz}$. Programs for conductance injection were written using a Dapview (Microstar Laboratory, Bellevue, WA) front-end and a language $\mathrm{C}$ backend. A variant of the dynamic-clamp technique (see below) was implemented using a DAP-5216a board (Microstar Laboratory, Bellevue, WA) at a rate of $10 \mathrm{kHz}$ connected to the Axoclamp 2A amplifier in current-clamp mode.

\subsection{Simulation of Synaptic Currents}

To recreate in vivo conditions, simulated synaptic conductances were injected into the recorded cell. These conductances were divided into two groups:

The first group of conductances consisted of two Ornstein-Uhlenbeck processes (constructed as in model, see above) adjusted to mimic the arrival of 16,563 glutamatergic and 3,376 GABAergic synaptic inputs distributed on the 
A

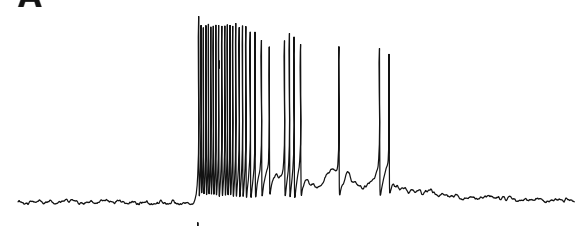

B

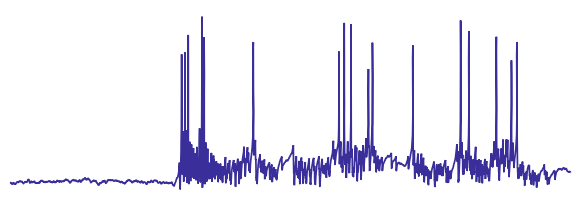

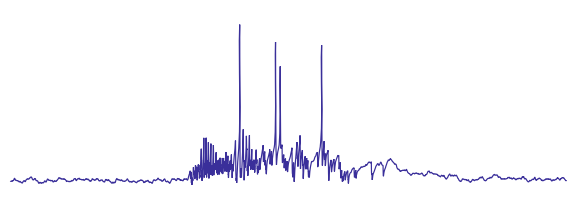

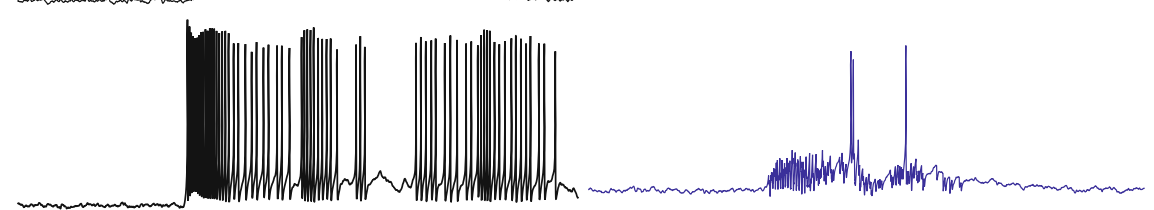

Fig. 1 Sample simulated voltage traces during reverberatory activity. A network of 26 pyramidal and 6 inhibitory cells was simulated and activated to generate reverberatory activity resembling 'up-states.' A: inhibitory neurons, B: excitatory neurons. Note the fast gammalike fluctuations in the membrane potential of interneurons. Membrane levels, fluctuation, and firing characteristics were matched to that observed in vivo (see text)

dendritic tree of a reconstructed multi-compartmental cortical cell, measured at the soma. Because of the slow dynamics of NMDA channels, and the large number of glutamatergic synapses taken into consideration, their contribution was approximated by a change in the mean level of inputs $\left(G_{\mathrm{e} 0}\right.$ and $\left.G_{\mathrm{i} 0}\right)$. The adjustment of the different conductances of synaptic background activity was done in order to match various physiological aspects of the data. Direct conductance measurements in vivo are also possible (see Piwkowska et. al. "Testing Methods for Synaptic Conductance Analysis Using Controlled Conductance Injection with Dynamic Clamp" in this volume). These conductances were injected using the dynamic-clamp technique continuously throughout the duration of the recordings (see also Chance and Abbott "Simulating In Vivo Background Activity in a Slice with the Dynamic Clamp," Robinson "Synaptic Conductances and Spike Generation in Cortical Cells," and Jaeger and Lin "Unraveling the Dynamics of Deep Cerebellar Nucleus Neurons with the Application of Artificial Conductances" in this volume).

The second group of conductances was injected using dynamic clamp in 'a reactive mode' to simulate the activity of small reverberatory network in which the real cell is embedded (see Canavier et. al. "Dynamic-Clamp-Constructed Hybrid Circuits for the Study of Synchronization Phenomena in Networks of Bursting Neurons" in this volume for a two-neuron hybrid circuit and Sadoc et. al. "Re-Creating In Vivo-Like Activity and Investigating the Signal Transfer Capabilities of Neurons: Dynamic-Clamp Applications Using Real-Time NEURON" in this volume). The conductances were injected in response to 
each action potential generated by the cell currently being recorded (hence 'reactive clamp').

$$
\begin{aligned}
I_{\text {feedback }}(t)= & G_{\mathrm{AMPA}}(t)\left(V(t)-E_{\mathrm{GLU}}\right)+G_{\mathrm{NMDA}}(t)\left(V(t)-E_{\mathrm{GLU}}\right) \\
& +G_{\mathrm{GABA}}(t)\left(V(t)-E_{\mathrm{GABA}}\right)
\end{aligned}
$$

such that if $V(t)>0$ (an action potential occurred) two Poisson sequences of synaptic release times were generated for glutamatergic and GABAergic synapses, respectively. Each sequence was computed such that

$$
\forall n \in[1 \ldots N], t_{n}=t_{n-1}-a \ln (1-r) \text { with } t_{0}=d
$$

where $N, a$, and $d$ are the number of synapses simulated, the mean inter-spike interval (ISI), and the dead time, respectively. The variable $r$ is a random number uniformly distributed between 0 and 1 . The feedback excitatory postsynaptic potentials (EPSPs) were modeled as the response of a single-cell representative of a population. Because each action potential of the recorded cell represented the synchronous firing of a small population of cells, it was assumed that the resulting postsynaptic effects were reliable rather than probabilistic. The synapses did not include short-term depression or facilitation. The conductance ratio of AMPA/NMDA excitatory synapses was 2-5 (McAllister and Stevens, 2000; Watt et al., 2000) so that AMPA and NMDA EPSPs typically had amplitudes of 1.5 and $0.5 \mathrm{mV}$, respectively.

The inhibitory postsynaptic potentials (IPSCs) were generated by interneurons simulating the activity of Calbindin D-28 k (CB) immunoreactive inhibitory cells that have local dendritic arbors and are believed to provide specific inhibition to the cortical module to which they belong (Conde et al., 1994; Gabbott and Bacon, 1996a, b; Gabbott et al., 1997; Krimer and GoldmanRakic, 2001). The conductances of these synapses were adjusted to mimic the experimental observations, and to provide fast and reliable feedback inhibition after each action potential (Krimer and Goldman-Rakic, 2001).

When an action potential was detected, the conductance for each receptor type was modified in order to account for the new synaptic releases such that

$$
G(t)=G_{\text {new }}(t)=G_{\text {old }}(t)+G_{\text {max }} \sum_{n=1}^{N} g\left(t-t_{n}\right)
$$

where $g(t)$ was an alpha function of time constant $2.7 \mathrm{~ms}$ for AMPA synapses, $70 \mathrm{~ms}$ for NMDA synapses, and $10 \mathrm{~ms}$ for $\mathrm{GABA}_{\mathrm{A}}$ synapses. Both AMPA and NMDA conductances shared the same $t$ series (co-activation of NMDA and AMPA receptors). $G_{\max }$ was the maximal conductance for each respective receptor type and could be adjusted by the experimenter. In the text, this quantity was referred to as $G_{\mathrm{AMPA}}, G_{\mathrm{GABA}}$, and $\mathrm{G}_{\mathrm{NMDA}}$. In the case of 
NMDA channels, however, $G_{\max }$ was voltage dependent (Jahr and Stevens, 1990) and was expressed as

$$
G_{\max }=\frac{G_{\mathrm{NMDA}}}{1+\frac{[\mathrm{Mg} 2+]}{3.57} \mathrm{e}^{-0.062 V}}
$$

with $[\mathrm{Mg} 2+]$ expressed in units of $\mathrm{mM}($ here $[\mathrm{Mg} 2+]=2)$.

\section{Results}

The composition of a reverberatory network is currently unknown. Calcium imaging experiments in vitro indicated that a relatively small number of cells (5-20) could synchronously join a reverberatory ensemble (Cossart et al., 2003; Ikegaya et al., 2004). The first step in our studies was to determine the size of the reverberatory network under in vivo conditions. We explored this issue by comparing computational network models of varying size and by eliciting reverberatory activity using extracellular stimulation in vitro.

\subsection{Network Size}

To study network properties of reverberatory activity in a model, we started with a network of 26 pyramidal neurons and 6 inhibitory neurons, created as specified in Section 2. To generate sustained activity, a short $(150 \mathrm{~ms})$ current pulse was given simultaneously to a few $(\sim 30 \%)$ model pyramidal neurons to mimic excitatory inputs from the thalamus, another cortical region, or the hippocampus. The conductances of the synaptic inputs were adjusted to obtain firing rates and pyramidal neuron membrane potential $\left(V_{\mathrm{m}}\right)$ averages and fluctuations (standard deviation) similar to those measured during in vivo up-states (Fig. 1 and Table 1).

Table 1 Comparison of sustained activity generated by our model with in vivo up-state data (Isomura et al., 2006; Luczak et al., 2007; Haider et al., 2006; Waters and Helmchen, 2006; Rudolph et al., 2007)

\begin{tabular}{lll}
\hline & $\begin{array}{l}26 \text { excitatory neuron } \\
\text { model }\end{array}$ & In vivo data \\
\hline Excitatory neuron firing rates & $10.4 \pm 1.3 \mathrm{~Hz}$ & $8-15 \mathrm{~Hz}$ \\
Inhibitory neuron firing rates & $34.5 \pm 5.3 \mathrm{~Hz}$ & $15-30 \mathrm{~Hz}$ \\
Average active state membrane potential & $-59.7 \pm 1.9 \mathrm{mV}$ & -50 to $-60 \mathrm{mV}$ \\
$\begin{array}{l}\text { Membrane potential fluctuations during } \\
\quad \text { active state }\end{array}$ & $4.69 \pm 0.52 \mathrm{mV}$ & $2-3 \mathrm{mV}$ \\
$\begin{array}{l}\text { Average 'down-state' membrane potential } \\
\text { 'Down-state' membrane potential }\end{array}$ & $-68.3 \pm 0.5 \mathrm{mV}$ & -65 to $-75 \mathrm{mV}$ \\
$\quad \begin{array}{ll}\text { fluctuations } \\
\text { Duration of active state }\end{array}$ & $1.03 \pm 0.20 \mathrm{mV}$ & $0.6-2 \mathrm{mV}$ \\
\hline
\end{tabular}


Because of the lack of intracellular data in the awake preparation during sustained activity, we used data obtained in vivo in the anesthetized animal to tune our model. The $V_{\mathrm{m}}$ fluctuations were the only statistic that did not fit to measured data levels if this network were to generate sustained activity, and therefore conductances were adjusted to make it as low as possible. The resulting model 'up-states' terminated spontaneously after 500-2,000 ms. Firing rates towards the end of the 'up-state' were constant until there was an abrupt end, indicating that activity did not just peter out.

Since the $V_{\mathrm{m}}$ fluctuations in this network were somewhat larger than those observed in vivo, we hypothesized that this network was smaller than those participating in reverberatory activity in vivo. To investigate how network size influences sustained activity statistics, the size was varied while keeping the proportion of excitatory and inhibitory neurons constant. Synaptic conductances were scaled proportionately to keep the overall synaptic inputs to each neuron approximately constant. This kept the average $V_{\mathrm{m}}$ of pyramidal neurons during sustained activity constant (Fig. 2A), but changed the $V_{\mathrm{m}}$ fluctuations (Fig. 2B), which were mainly determined by the conductances of single synaptic events. The $V_{\mathrm{m}}$ fluctuations reached the in vivo levels for networks with 39 excitatory neurons, and appeared to reach an asymptote within the in vivo measured range. The firing rates of both excitatory and inhibitory neurons were larger in small networks (Fig. 2C). This may be due to the larger size of each individual synaptic conductance, which may allow the neuron to cross threshold more often even though the average input is approximately the same. The average $V_{\mathrm{m}}$ of inhibitory neurons, unlike that of pyramidal neurons, increased as network size decreased (Fig. 2A). This increase may be due to the slightly higher pyramidal neuron firing rates in the smaller networks, which cause a non-balanced increase in the number of excitatory inputs to the inhibitory neurons. Another statistic that changed with network size was reverberatory activity duration, which increased for larger networks (Fig. 2D). These results show that a relatively small number of cells (39 pyramidal neurons and 9 interneurons) can generate and sustain reverberatory activity comparable to up-states observed in vivo. Smaller networks required larger individual synaptic events than those observed in vivo to generate sustained activity.

\subsection{Properties of Reverberations In Vitro}

To elucidate the amplitude and temporal dynamics of reverberations, reverberatory activity was elicited by stimulating the afferents to a neuron recorded intracellularly in vitro. The extracellular stimulating electrode was placed in layer 5, about $100 \mu \mathrm{m}$ from the cell body of the recorded neuron. In the control medium, the stimulation elicited a monosynaptic compound EPSP of approximately $15 \mathrm{mV}$ amplitude followed by a trail of multisynaptic EPSPs. These EPSPs were not affected by bath application of bicuculline $(20 \mu \mathrm{M}$, not shown) but were greatly reduced by the application of DNQX $(10 \mu \mathrm{M})$ that left only a 

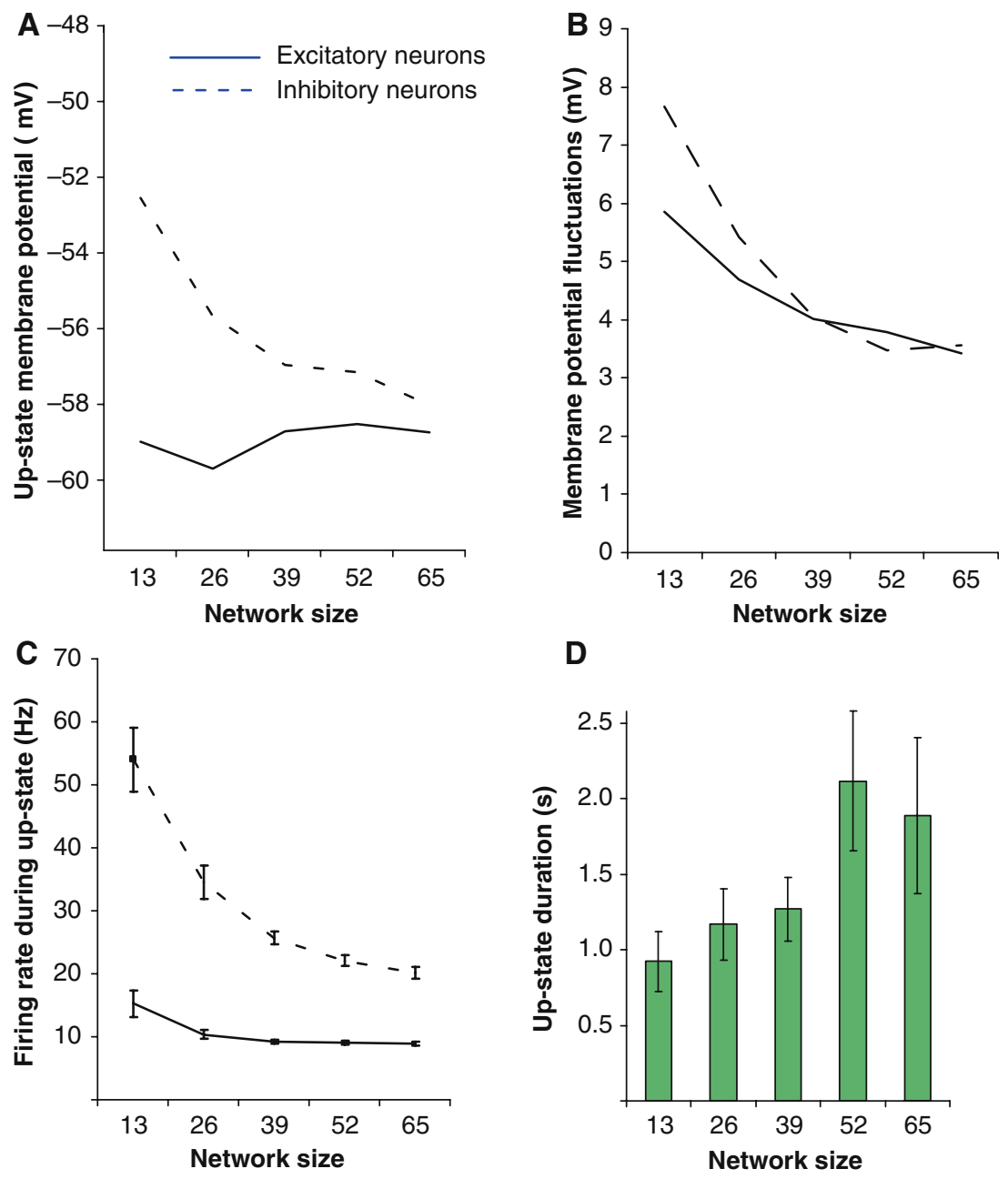

D

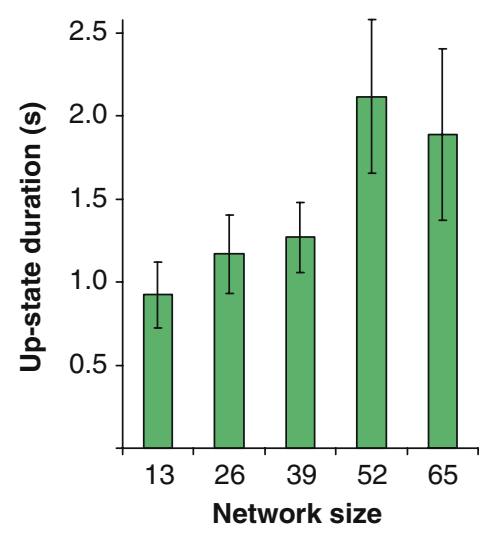

Fig. 2 Influence of network size on reverberatory activity characteristics. Network size was varied ( $x$-axis is number of excitatory cells - inhibitory cells were varied proportionately) and several characteristics of the 'up-states' were measured. A: average membrane potential, B: Membrane fluctuations (standard deviation of $V_{\mathrm{m}}$ ), C: firing rates, and $\mathbf{D}$ : duration of the sustained activity. Standard errors in panels A and B are within - the thickness of the lines and have been omitted. Adapted from Navratilova and Fellous (2008)

monosynaptic NMDA component (Fig. 3A middle). The application of APV $(50 \mu \mathrm{M})$ abolished the response entirely (Fig. 3A, right). In 5/7 cells, afferent stimulation was followed by long latency excitatory inputs from neighboring pyramidal cells. These EPSPs could occur early and overlap with the repolarizing phase of the compound EPSP or could occur as late as $700 \mathrm{~ms}$ after stimulus onset, well after the compound EPSPs terminated. Some of these EPSPs may be 
A Control Bicuculline + DNQX Bicuculline + DNQX + APV

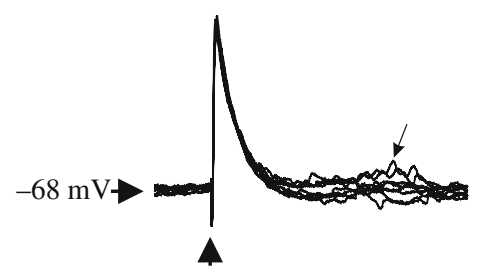

B

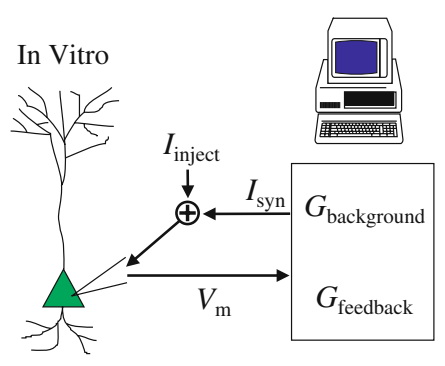

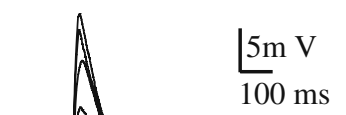

$\frac{5 \mathrm{~m} \mathrm{~V}}{100 \mathrm{~ms}}$

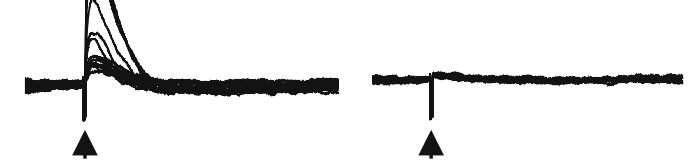

C

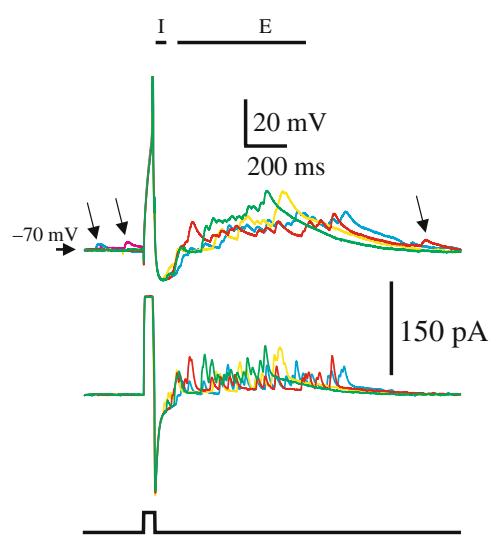

Fig. 3 Evidence for reverberatory activity in the in vitro preparation. A: Responses of a layer 5 pyramidal cell to a synaptic stimulation (up arrow) provided by an extracellular electrode placed about $100 \mu \mathrm{M}$ from the soma in layer 5. Left: control condition (eight superimposed traces). Note the presence of a trail of EPSPs following the monosynaptic response (arrow). Middle: The wash-in of bicuculline $(20 \mu \mathrm{M})$ and DNQX $(10 \mu \mathrm{M})$ reduced the amplitude of the monosynatic response and suppressed the trail of EPSPs. Right: the remaining synaptic response was abolished by $50 \mu \mathrm{M}$ APV indicating that it was mediated by NMDA receptor activation. B: schematic illustration of our hybrid system. At each time step $(0.1 \mathrm{~ms})$, a dedicated computer computed the values of two synaptic conductances. The first $G_{\text {background }}$ mimicked the continuous background activity of distant cells; the second $G_{\text {feedback }}$ was computed each time an action potential was emitted by the cell recorded in vitro (reactive clamp, see Section 2). C: Reactive clamp responses with mixed AMPA, NMDA, and GABA conductances (four superimposed traces). Values for synaptic conductances were $G_{\mathrm{AMPA}}=$ $2.1 \mathrm{nS}, G_{\mathrm{NMDA}}=0.4 \mathrm{nS}$, and $G_{\mathrm{GABA}}=7.1 \mathrm{nS}$. Lower traces represent the current pulse injected to the cell to initiate a single action potential. The middle trace represents the sum of the current pulse, and the current computed and injected by the reactive clamp. The upper trace shows the membrane potential of the cell. Note the presence of spontaneous EPSPs (arrows). The horizontal bars labeled I and E indicate the average time course of the inhibitory and excitatory feedback inputs, respectively. Adapted from Fellous and Sejnowski (2003)

directly related to the cell's own spiking, but it is likely that most are due to multi-synaptic reverberations from other cells that have been simultaneously activated by the extracellular electrode. Feedforward inhibition was activated by the stimulation and was 'hidden' by the monosynaptic EPSP (Fellous and 
Sejnowski, 2003). Because the onset times of the feedback IPSCs could not be directly measured, due to the monosynaptic response, we estimated their distribution (mean $40 \pm 20 \mathrm{~ms}$ ).

\subsection{Reverberatory Ensemble Using Reactive Clamp}

In order to study the impact of the reverberatory 'trail' on persistent activity, we used a variant of the dynamical clamp technique (Fig. 3B). A neuron was recorded intracellularly in current-clamp mode. A dedicated computer was programmed to detect the occurrence of an action potential (voltage crossing $0 \mathrm{mV}$ ) and to dynamically react to each action potential by generating a train of mixed IPSCs and EPSCs that was injected in the neuron. The time distribution of the simulated excitatory synaptic events was assumed to be Poisson with a mean and dead time matching the experimental data.

Compatible with the simulation results presented above, excitatory AMPA and NMDA components were generated by a population of 40 synapses together constituting a Poisson train of EPSPs with mean interval of $15 \mathrm{~ms}$ and a dead time of $100 \mathrm{~ms}$. Because the average synaptic interval of $15 \mathrm{~ms}$ $(66 \mathrm{~Hz})$ corresponds to the discharge of 40 cells, each of these feedback cells is assumed to fire only once during $15 \times 40=600 \mathrm{~ms}$ immediately following a single spike by the real cell. For each spike of the real cell, one and only one feedback EPSP/spike from each of the 40 cells is generated, so that in principle the firing rate of each of the simulated microcircuit feedback cells is always kept identical to the firing rate of the real cell (no matter what this firing rate is).

Feedback IPSPs were generated by a population of five GABAergic synapses with a mean interval of $10 \mathrm{~ms}$ and a dead time of $15 \mathrm{~ms}$. In 6/21 exploratory experiments these values were set empirically so that excitatory mean intervals and dead times ranged from $12-18$ and $90-150 \mathrm{~ms}$, respectively, and inhibitory mean intervals and dead times ranged from 8-12 and 10-20 ms, respectively. The results obtained under these conditions were qualitatively similar to those obtained with the chosen standard intervals and dead times mentioned above.

The $\mathrm{GABA}_{\mathrm{A}}$ inhibitory feedback synaptic currents were distributed in time according to our experimental estimates above (Fellous and Sejnowski, 2003). Their mean discharge ISI was set to $10 \mathrm{~ms}$ with a deadtime of $15 \mathrm{~ms}$. Fig. 3 shows the compound feedback injected by the reactive clamp in response to one elicited spike. A fast initial GABA component is followed by a slow NMDAmediated component topped by AMPA EPSPs. Note that this curve is somewhat different from the data shown in Fig. 3. The EPSPs in Fig. 3C are lower in amplitude and the NMDA depolarization is smaller than the ones obtained with reactive clamp. The difference is due to the fact that the reactive clamp implements the in vivo situation where all the cells of the microcircuits are healthy and where all synaptic connections are functional. This is unlikely to be true in vitro. The fast GABA inhibition visible after the spike is more 
pronounced than in Fig. 3 due to the fact that the experimental data included a powerful feedforward compound EPSP which partially masked inhibition.

Cells in vivo have large subthreshold membrane fluctuations (standard deviation of approximately $4 \mathrm{mV}$ ), a mean potential typically around $-60 \mathrm{mV}$, spontaneous and irregular firing $(0.3-2 \mathrm{~Hz}$ in prefrontal cortex with a coefficient of variation approaching 1.0), and a low input resistance (about $40 \mathrm{M} \Omega$ ) (Paré et al., 1998; Destexhe and Paré, 1999; Fellous et al., 2003). These properties arise from the background synaptic inputs coming from other cells in the circuit. These aspects of in vivo activity can be effectively recreated in the in vitro preparation (Destexhe et al., 2001) by injecting the excitatory and inhibitory background synaptic activity as random conductance processes (see methods) into a neuron using a standard dynamical clamp protocol. The mean and standard deviation of these conductances were adjusted to yield in vivo-like activity.

\subsection{Spontaneous Sustained Activity}

Figure 4 shows an example of a cell recorded in vitro, to which synaptic background activity was added $\left(G_{\mathrm{e} 0}=10 \mathrm{nS}, G_{\mathrm{i} 0}=21 \mathrm{nS}, \sigma_{\mathrm{e}}=3 \mathrm{nS}\right.$, and $\left.\sigma_{\mathrm{i}}=7.5 \mathrm{nS}\right)$. The cell fired at $0.4 \mathrm{~Hz}(0.46 \pm 0.1 \mathrm{~Hz}, n=19)$ with a $\mathrm{CV}$ of $0.71(0.72 \pm 0.1$, $n=16)$, its membrane potential was depolarized to $-66 \mathrm{mV}(-64.3 \pm 1.53 \mathrm{mV}$, $n=19)$, the membrane showed large fluctuations of $4.1 \mathrm{mV}$ standard deviation $(4.3 \pm 0.8, n=19)$, and its input resistance was $42 \mathrm{M} \Omega(37.9 \pm 6.4, n=19)$, without the noise the resting membrane potential was $-71 \mathrm{mV}(-69.8 \pm 3.1$, $n=19)$ and its input resistance was $184 \mathrm{M} \Omega(157 \pm 32, n=19)$. The lower trace shows the background synaptic current computed by the dynamic clamp. Note the presence of action potentials in the injected current trace, a hallmark of the dynamical clamp technique. The synaptic background noise represented the aggregate activity of a large population of pyramidal cells and interneurons located outside the cortical module where the cell was located. Unlike the feedback activity presented in Fig. 3, this activity was assumed to not depend on the specific firing pattern of the cell recorded, and its parameters (mean and standard deviation of excitatory and inhibitory processes) were typically kept constant. In this preparation, background synaptic activity alone was not sufficient to explain the high CV typically observed in vivo.

When the model of the cortical feedback was added along with synaptic background activity, the cell exhibited short and fast sequences of action potentials riding on a small NMDA-mediated feedback depolarization $\left(G_{\mathrm{AMPA}}=1.5 \mathrm{nS}, G_{\mathrm{NMDA}}=0.5 \mathrm{nS}\right.$, and $\left.G_{\mathrm{GABA}}=6.0 \mathrm{nS}\right)$. These sequences lasted typically less than $2 \mathrm{~s}(1.3 \mathrm{~s} \pm 0.5 \mathrm{~s}, n=47,4$ cells, Fig. 4B lower trace, arrow) and the firing rate increased to in vivo-like values $(1.2 \pm .64 \mathrm{~Hz}, n=19)$. Because of the introduction of short ISIs, the CV increased to values typically observed in vivo (0.92 $\pm 0.2, n=16$ ) (Softky and Koch, 1993; Holt et al., 1996; Shadlen and Newsome, 1998). These fast sequences were akin to in vivo 'up-states' and 
A

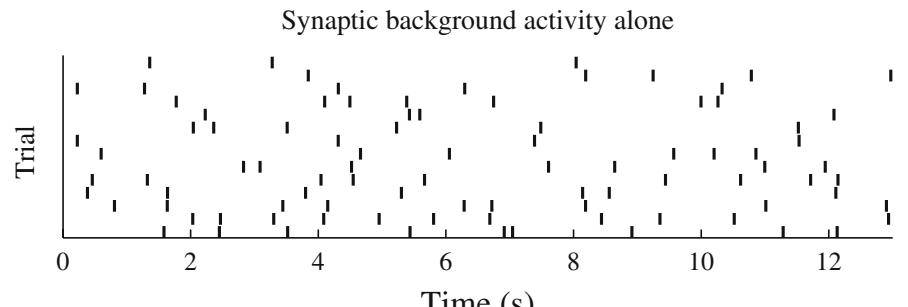

Time (s)

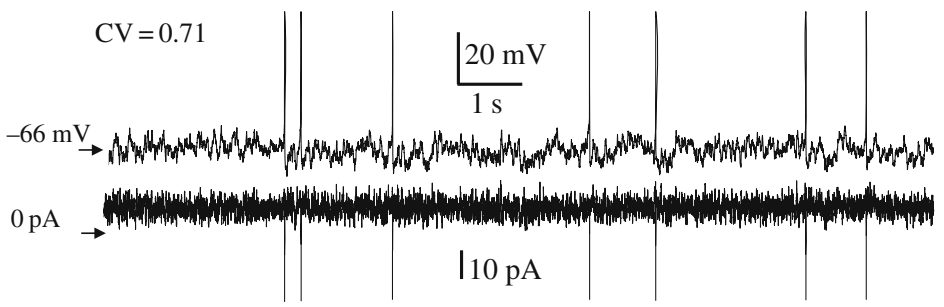

B

Synaptic background activity + reactive clamp
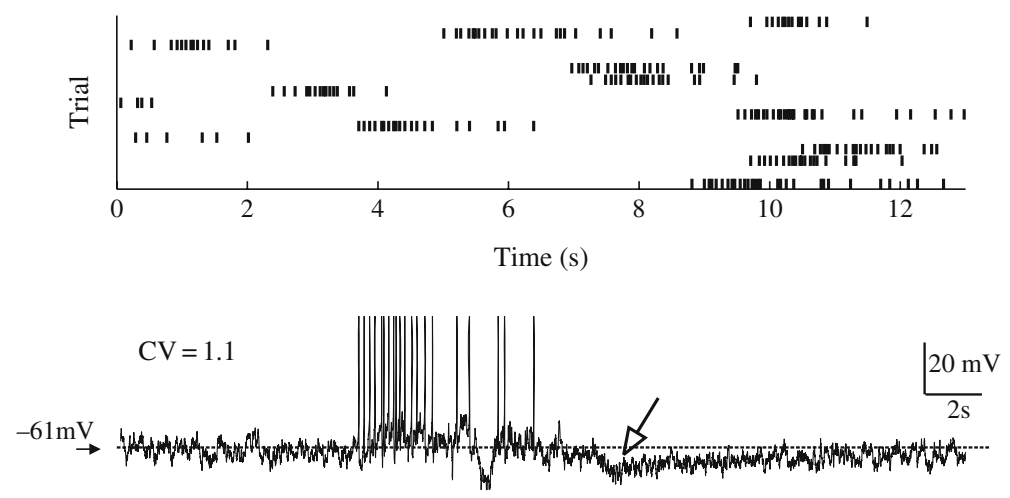

Fig. 4 Spontaneous spiking of a layer 5 pyramidal cell undergoing background and feedback synaptic noise. A: Example of a cell undergoing synaptic background noise only $\left(G_{\mathrm{e} 0}=10 \mathrm{nS}\right.$, $G_{\mathrm{i} 0}=21 \mathrm{nS}, \sigma_{\mathrm{e}}=3 \mathrm{nS}$, and $\left.\sigma_{\mathrm{i}}=7.5 \mathrm{nS}\right)$. The rastergram shows the spiking activity of this cell during $182 \mathrm{~s}$ (represented as 14 trials of $13 \mathrm{~s}$ each). An example of the membrane voltage is shown below. The current computed by the dynamic clamp is shown below the voltage trace. In this condition, the $\mathrm{CV}$ of this cell was 0.71 . B: Addition of reverberatory activity under reactive clamp. The cell now shows spontaneous bouts of sustained activity lasting typically longer than a second (see rastergram). A sample voltage trace is shown below the rastergram. Note the presence of a slow intrinsic hyperpolarizing current (not found in the computergenerated synaptic current trace, not shown) that terminates the reverberatory activity (open arrow). In this condition the $\mathrm{CV}$ was 1.1 due to the introduction of very fast ISIs. All panels are from the same cell. Adapted from Fellous and Sejnowski (2003)

were followed by long periods of spiking silence. Since the model of the synaptic background activity was derived from in vivo intracellular data in the anesthetized animal, the cells modeled here should reflect low levels of dopamine (Paré et al., 1998; Fellous et al., 2003). Recent in vitro studies demonstrated that 
dopamine increased the excitability of prefrontal cortex (PFC) cells (Yang and Seamans, 1996; Shi et al., 1997; Henze et al., 2000) and increased the amount of NMDA current (Cepeda et al., 1993; Zheng et al., 1999; Seamans et al., 2001) elicited by extracellular stimulation. An increase in the average membrane potential $(+5 \mathrm{mV})$ and an increase in the feedback NMDA current $(+30 \%)$ mimicking the effect of higher, in vivo-behaving-like dopamine levels, yielded an increase in the occurrence and duration of the fast sequences (Fig. 4B). Typically, these sequences resembled spontaneous dopamine-dependent 'upstates' observed in vivo in prefrontal cortex (Lewis and O'Donnell, 2000), lasted substantially longer ( $3.2 \pm 0.9 \mathrm{~s}, n=61$, five cells) than in baseline conditions and the CV increased slightly $(1.1 \pm 0.1, n=9)$.

Reverberatory activity was initiated by a fast sequence of action potentials that recruited a large excitatory feedback. It was terminated by the activation of a slow hyperpolarizing intrinsic current (Fig. 4B, open arrow). Although this current was not pharmacologically characterized in this study it was primarily activated after a large amount of spiking,and likely included a calciumactivated potassium current. The parameters of the background and reactive components were then fixed for each cell recorded, and further explorations of the conditions of initiation of these reverberations were conducted.

\subsection{Stimulus-Driven Elicitation of Sustained Activity}

In a typical working memory task, cells in frontal cortices are transiently activated by the presentation of a cue, and continue to fire for several seconds after the cue has been removed, until the behavioral response is initiated. In order to assess the ability of a PFC cortical module to sustain activity, we simulated the cue and the behavioral response phases of a working memory task by positive and negative current injection, respectively. In Fig. 5, a PFC cell placed in realistic in vivo conditions fired in a sustained manner, long after the cue stimulus was turned off, until the simulated response was triggered $\left(G_{\mathrm{e} 0}=\right.$ $12 \mathrm{nS}, G_{\mathrm{i} 0}=20 \mathrm{nS}, \sigma_{\mathrm{e}}=2.8 \mathrm{nS}, \sigma_{\mathrm{i}}=7.1 \mathrm{nS}, G_{\mathrm{AMPA}}=1.6 \mathrm{nS}, G_{\mathrm{NMDA}}=0.5 \mathrm{nS}$, and $G_{\mathrm{GABA}}=6.8 \mathrm{nS}$ ). This behavior was elicited in 21 of the 32 cells tested. In these cells, the firing rate during the delay period was typically lower than during the presentation of the cue. Two of the 32 cells tested were strongly adapting and could not be stimulated to produce sustained activity while in a regime of spontaneous background similar to the ones observed in vivo. In nine cells, the short cue-depolarization failed to promote sustained spiking, and instead activated the slow hyperpolarization previously noted. In those cells, the firing rates during the delay period were decreased.

A detailed analysis of the trials during which sustained activity was not achieved revealed that sustained activity depended strongly on the number of action potentials generated during the cue period (Fellous and Sejnowski, 2003). For a low number of action potentials, or for action potentials sequences of 

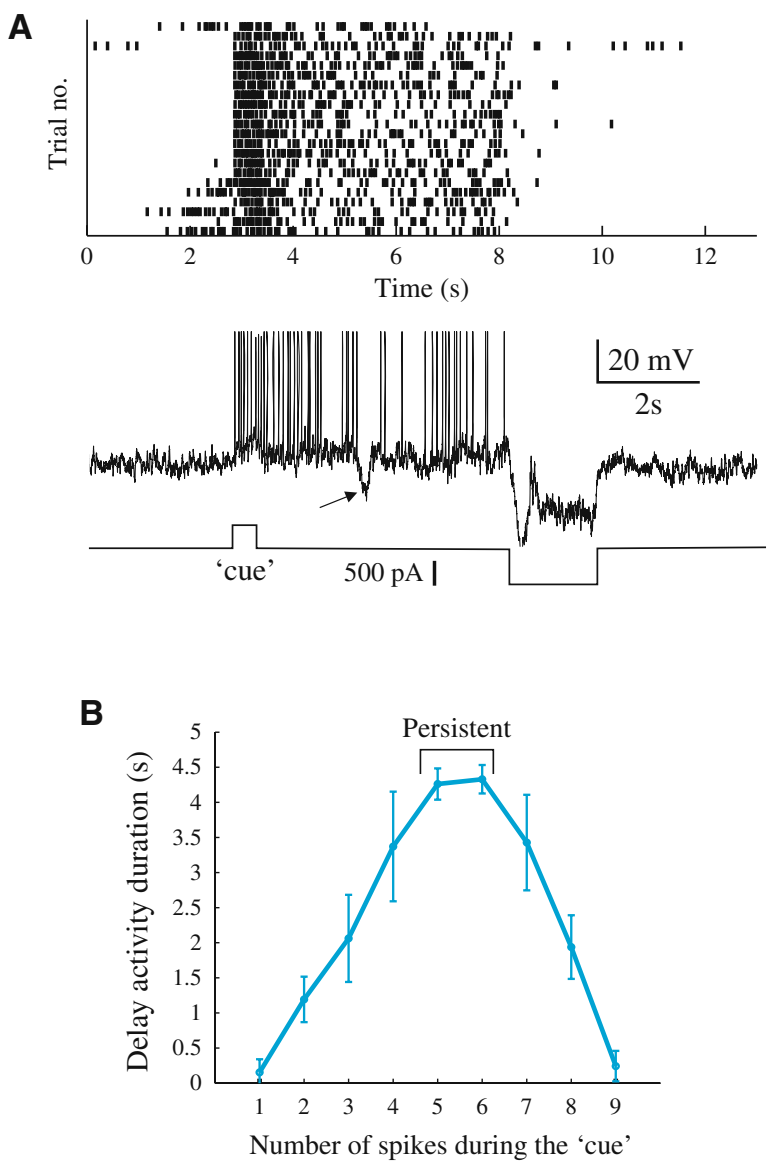

Fig. 5 Simulated delayed match-to-sample task in layer 5 pyramidal cells. A: A pyramidal cell was placed in in vivo like conditions by injecting background synaptic inputs $\left(G_{\mathrm{e} 0}=12 \mathrm{nS}, G_{\mathrm{i} 0}=\right.$ $20 \mathrm{nS}, \sigma_{\mathrm{e}}=2.8 \mathrm{nS}, \sigma_{\mathrm{i}}=7.1 \mathrm{nS}$, and $51 \mathrm{M} \Omega$ input resistance $)$ and reactive feedback $\left(G_{\mathrm{AMPA}}=1.6\right.$ $\mathrm{nS}, G_{\mathrm{NMDA}}=0.5 \mathrm{nS}$, and $G_{\mathrm{GABA}}=6.8 \mathrm{nS}$ ). The cell was then injected a current pulse lasting $400 \mathrm{~ms}$ simulating the 'cue' and a hyperpolarizing current pulse lasting $1.8 \mathrm{~s}$. The cell showed sustained firing for the duration of the delay period $(4.5 \mathrm{~s})$. Note the occurrence of large inhibitory events (arrow) resulting from the random synchronization between background and feedback inhibition. The background firing rate of the cell was $1.1 \mathrm{~Hz}$, its firing rate during the delay period was $6.2 \mathrm{~Hz}$, the rastergram shows 18 of 44 trials. B: Group data for five cells matched for their input resistance $(40 \pm 6 \mathrm{M} \Omega)$ and background firing rate $(0.7 \pm 0.4 \mathrm{~Hz})$. The curve shows the average duration of the spiking activity after the cue offset, as a function of the number of action potentials generated during the cue. Persistent activity was most reliably achieved for five and six actions potentials. Adapted from Fellous and Sejnowski (2003)

large ISIs, the reverberatory activity was not sufficient to trigger additional spikes, as occurs during spontaneous activity. A large number of action potentials (7-8) activated an intrinsic slow hyperpolarizing current that kept the cells below threshold, despite a large amount of synaptic feedback. Intermediate 
amounts of spiking (5-6 in Fig. 5B) could sustain the activity of the cell for several seconds. Group data on five cells matched for their input resistance (40 $\pm 6 \mathrm{M} \Omega$ with synaptic background) and background firing rate $(0.7 \pm$ $0.4 \mathrm{~Hz}$ ) revealed that persistent activity optimally occurred when five or six action potentials were generated during the cue period (Fig. 5B). The inverted U-shape nature of the curve was qualitatively reproduced in most cells recorded, but its position and width on the $x$-axis varied greatly from cell to cell.

\subsection{Regulation of Reverberatory Activity Level by Inhibition}

Prefrontal cortical pyramidal cells recorded in vivo during working memory tasks show a wide range of firing rates during the delay period. In the same cell, firing rates might vary from baseline levels for non-preferred stimuli, to firing rates 10 times larger than control for preferred stimuli (Goldman-Rakic, 1995). Other cells modulate their firing rate in relation to the luminance of distracting stimuli (Constantinidis et al., 2001). The gain of a pyramidal cell depends on the standard deviation of the excitatory and inhibitory synaptic background noise that it receives (Chance et al., 2002; Fellous et al., 2003, Chance and Abbott "Simulating In Vivo Background Activity in a Slice with the Dynamic Clamp" in this volume). In prefrontal cortical cells, an increase in the standard deviation of the background inhibitory inputs $\left(\sigma_{i}\right)$ mimicking an increase in inhibitory correlation was particularly effective in modifying the shape of the input/output curve of pyramidal cells recorded in vitro under in vivo like conditions (Fellous et al., 2003). Figure 6A shows an example of the influence of $\sigma_{\mathrm{i}}$ on the response of a cell that was placed in the nominal conditions of our experiments (Fig. 4, $G_{\mathrm{e} 0}=23 \mathrm{nS}, G_{\mathrm{i} 0}=31 \mathrm{nS}, \sigma_{\mathrm{e}}=2.5 \mathrm{nS}, \sigma_{\mathrm{i}}=6.5 \mathrm{nS}, G_{\mathrm{AMPA}}=1.2 \mathrm{nS}, G_{\mathrm{NMDA}}=$ $0.6 \mathrm{nS}, G_{\mathrm{GABA}}=6.0 \mathrm{nS}$, and the standard deviation of the membrane potential was $3.1 \mathrm{mV}$ ). As $\sigma_{\mathrm{i}}$ increased, the maximal value of the firing rate increased, and the slope of the frequency/current curve increased so that for low-input current the firing remained relatively unchanged, and for higher current intensity the firing rate in the two conditions became significantly different going from $20 \mathrm{~Hz}$ to about $40 \mathrm{~Hz}$ (the standard deviation of the membrane potential was increased to $5.3 \mathrm{mV}$, primarily in the hyperpolarizing direction). Firing rates were computed from 3-s-long current injections (excluding the first $500 \mathrm{~ms}$ ). In the cue-elicited sustained activity experiments, with the low $\sigma_{\mathrm{i}}$ value $(6.5 \mathrm{nS})$ the cell exhibited a background firing rate of $0.5 \mathrm{~Hz}$, and a delay firing rate of about $8 \mathrm{~Hz}$. When $\sigma_{\mathrm{i}}$ was increased to $25 \mathrm{nS}$, the background firing rate did not qualitatively change $(0.9 \mathrm{~Hz})$ but the firing rate during the delayed period increased to $31 \mathrm{~Hz}$ (Fig. 6B). The signal-to-noise ratio in this cell could therefore be tuned and was increased in this experiment by about $110 \%$ by increasing $\sigma_{\mathrm{i}}$. Similar results were obtained for three other pyramidal cells with increases in signal-to-noise ratios of 20,32, and 59\%. These results suggest that the amount of correlation in the background inhibitory inputs might be key to determining 
A

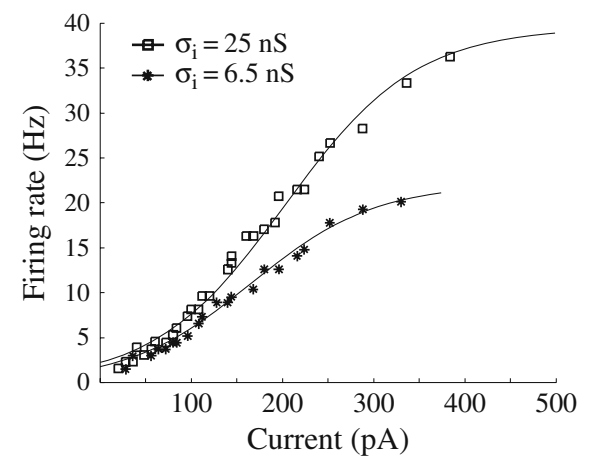

B $\sigma_{\mathrm{i}}=6.5 \mathrm{nS}$ $\sigma_{\mathrm{i}}=25 \mathrm{nS}$
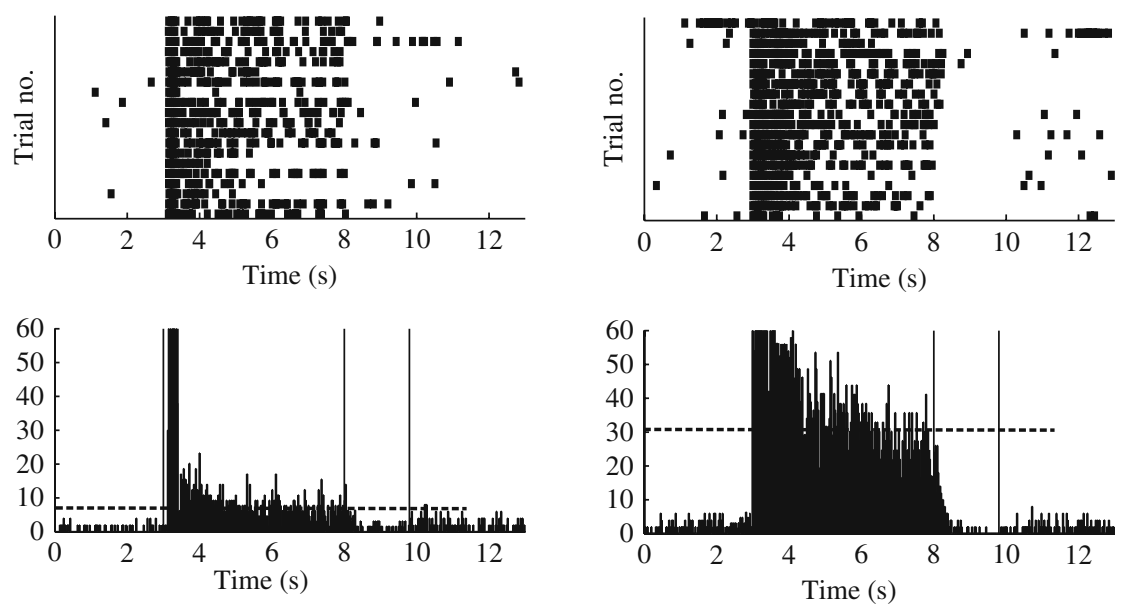

Fig. 6 The firing rate during the delay period activity can be modulated by the correlation of the background inhibitory synaptic noise. A: Average firing rate of a pyramidal cell in response to 3 -s-long current pulses of varying amplitude for low $\left(\sigma_{\mathrm{i}}=6.5 \mathrm{nS}\right.$, stars $)$ and high $\left(\sigma_{\mathrm{i}}=25 \mathrm{nS}\right.$, open squares) standard deviation of the background synaptic noise $\left(G_{\mathrm{e} 0}=23 \mathrm{nS}, G_{\mathrm{i} 0}=31 \mathrm{nS}\right.$, $\sigma_{\mathrm{e}}=2.5 \mathrm{nS}, G_{\mathrm{AMPA}}=1.2 \mathrm{nS}, G_{\mathrm{NMDA}}=0.6 \mathrm{nS}, G_{\mathrm{GABA}}=6.0 \mathrm{nS}$, and $37 \mathrm{M} \Omega$ input resistance). This standard deviation corresponds to the amount of correlation in the background synaptic inputs (Fellous et al., 2003). B: The same cell was injected with cue and response pulses to elicit sustained activity as in Fig. 5 . When $\sigma_{\mathrm{i}}$ was low, the cell sustained activity at $8 \mathrm{~Hz}$ during the delay period, and its background firing rate before the cue was $0.5 \mathrm{~Hz}$. When $\sigma_{\mathrm{i}}$ was high, the cell sustained activity at $31 \mathrm{~Hz}$ and its background activity before the cue was $0.9 \mathrm{~Hz}$. Adapted from Fellous and Sejnowski (2003)

the firing rate of the cell during the delay period (see also Jaeger and Lin "Unraveling the Dynamics of Deep Cerebellar Nucleus Neurons with the Application of Artificial Conductances" in this volume). 


\section{Discussion}

Using computer simulations and a hybrid in vitro preparation we reproduced the reverberatory activity occurring in small cortical networks during selfsustained activity. Both studies indicated that about 40 excitatory cells were sufficient to mimic the membrane and firing statistics seen in vivo. Cells placed in such networks responded to a brief depolarization with an increase in firing rate that outlasted the depolarization, mimicking the activity of a cell responding to its preferred stimulus during the delay period of a working memory task in the behaving monkey. Some cells recorded with the reactive clamp technique showed 'off' responses and their firing rates decreased during the delay period due to the activation of a slow intrinsic hyperpolarizing current. Finally, we showed that background inhibition could change the input/output gain of single cells, and modulate the level of activity during sustained activity without significant changes in background baseline activity.

In modeling work we also showed that intrinsic currents such as the H-current could contribute to the initiation of sustained activity (Navratilova and Fellous, 2008). The H-current made the initiation of the reverberations more likely to occur following excitatory inputs. Also, since the H-current is activated at hyperpolarized potentials an inhibitory volley prior to excitatory inputs enhanced its activation and further increased the probability of generating sustained activity. The $\mathrm{H}$-current did not have an effect on other properties of sustained activity, such as the firing rate or duration.

The simulation and in vitro results presented above suggest the following sequence of events bringing into play both intrinsic currents and network dynamics (see Tobin et. al. "Using the Dynamic Clamp to Explore the Relationship Between Intrinsic Activity and Network Dynamics," Sadoc et. al. "Re-Creating In Vivo-Like Activity and Investigating the Signal Transfer Capabilities of Neurons: Dynamic-Clamp Applications Using Real-Time NEURON," and White et al. "Using "Hard" Real-Time Dynamic Clamp to Study Cellular and Network Mechanisms of Synchronization in the Hippocampal Formation" in this volume for other examples). Reverberatory activity is initiated by brief depolarizations of a subset of neurons belonging to the ensemble. In cells containing an $\mathrm{H}$-current, this depolarization is facilitated, especially if a short preceding hyperpolarization is present (Navratilova and Fellous, 2008). Provided that the level of depolarization is within a certain range, action potentials in the initiator cells will generate sufficient postsynaptic NMDA currents to recruit the other members of the assembly, including inhibitory cells. Background noise has been shown to modify the gain of the input/output curve (Chance et al., 2002; Fellous et al., 2003) and to make the cell more sensitive to transient inputs as short as $30 \mathrm{~ms}$ (Fellous et al., 2003). As noted anecdotally in previous work, inhibition, possibly due to its shunting nature, is more effective at controlling the gain than excitation (Fellous et al., 2003). We found that the amount of correlations in the inhibitory background 
inputs (not belonging to the assembly, and modeled by the standard deviation of the inhibitory noise) controls the firing rate of individual cells in the assembly. Recent evidence has highlighted the predominant role of inhibition during reverberatory activity in vitro and in vivo (Piwkowska et al., 2008). The firing of the cells during the reverberation triggers slow intracellular calcium accumulation and activates calcium-dependent potassium currents. These currents build up and eventually shut down individual cells. A complementary role for calcium accumulation has been proposed elsewhere on theoretical ground (Mongillo et al., 2008). After a critical number of cells have shut down, the whole assembly shuts down due a lack of NMDA-dependent reverberatory drive, and the small network enters a quiet state. Our results could explain findings such as the increased duration of the reverberation by dopamine released from the ventral tegmental area (Lewis and O,Donnell, 2000). If, as our results suggest, reverberatory activity relies on prompt NMDA-dependent excitatory feedback within a small population of interconnected neurons, then modulation by dopamine depolarizes the cells, increases NMDA currents and results in an increase of the duration of sustained activity (Section 3 and Fig 4B).

These results and hypothetical mechanism are of course contingent on several assumptions made by the reactive clamp and computational models including the exact number of reverberatory synapses used and their dynamics. In light microscopy anatomical studies of the rat medial prefrontal cortex, a cortical module $(50 \times 50 \mu \mathrm{m})$ had about 80 pyramidal cells and about 16 interneurons (Gabbott and Bacon, 1996a, b; Gabbott et al., 1997). Since about 40 of these 80 pyramidal cells are in layer $5 / 6$, and since most layer $5 / 6$ cells are connected to other layer $5 / 6$ cells, our population of synapses modeled the excitatory feedback within a single cortical module (Melchitzky et al., 1998). Further work is needed to compare the prefrontal cortex studied here with other cortical or subcortical areas that also exhibit persistent activity. While synapses in the model explicitly included stochasticity, the unreliability of the synapses in the reactive clamp experiments was captured by the Poisson nature of the feedback. However, the sizes of the individual e/ipsps were constant. Recent work has shown that short-term plasticity may be of functional relevance in removing or restoring temporal correlations within spike trains (Goldman et al., 2002) and further work is required to assess its impact on reverberatory activity.

Although this study focused on the spontaneous and stimulus-driven sustained activity in the PFC during a working memory task, it may apply to other systems and behaviors and can shed light on the functional nature of local microcircuits in other parts of the cortex. A cortical cell receives at least two functionally distinct kinds of inhibition: The first is a feedforward inhibition generated by the background synaptic noise from distant microcircuits. This input varies slowly and its standard deviation (amount of correlation) modulates the gain of the postsynaptic cell. The second kind of inhibition is feedback inhibition local to the microcircuit and its role is to control the amount of reverberation within the microcircuit. Recent experimental evidence supports 
the presence of feedforward and feedback inhibition during working memory tasks (Constantinidis et al., 2002), and further experimental and theoretical studies should explore the consequences of this inhibition for the function of cortical microcircuits.

\section{Glossary of terms}

NMDA: N-methyl D-aspartate, AMPA: $\alpha$-amino-3-hydroxyl-5-methyl-4isoxazole-propionate, GABA: gamma-amino butyric acid, CB: Calbindin D-28k, DNQX: 6,7-Dinitroquinoxaline-2,3-dione, APV: (2R)-amino-5phosphonovaleric acid, CV: Coefficient of variation.

\section{References}

Casagrande VA, Xu X, Sary G (2002) Static and dynamic views of visual cortical organization. Prog Brain Res 136:389-408.

Cepeda C, Buchwald NA, Levine MS (1993) Neuromodulatory actions of dopamine in the neostriatum are dependent upon the excitatory amino acid receptor subtypes activated. Proc Natl Acad Sci USA 90:9576-9580.

Chance FS, Abbott LF, Reyes AD (2002) Gain modulation from background synaptic input. Neuron 35:773-782.

Conde F, Lund JS, Jacobowitz DM, Baimbridge KG, Lewis DA (1994) Local circuit neurons immunoreactive for calretinin, calbindin D-28 k or parvalbumin in monkey prefrontal cortex: distribution and morphology. J Comp Neurol 341:95-116.

Constantinidis C, Franowicz MN, Goldman-Rakic PS (2001) The sensory nature of mnemonic representation in the primate prefrontal cortex. Nat Neurosci 4:311-316.

Constantinidis C, Williams GV, Goldman-Rakic PS (2002) A role for inhibition in shaping the temporal flow of information in prefrontal cortex. Nat Neurosci 5:175-180.

Cossart R, Aronov D, Yuste R (2003) Attractor dynamics of network UP states in the neocortex. Nature 423:283-288.

Destexhe A, Paré D (1999) Impact of network activity on the integrative properties of neocortical pyramidal neurons in vivo. J Neurophysiol 81:1531-1547.

Destexhe A, Babloyantz A, Sejnowski TJ (1993) Ionic mechanisms for intrinsic slow oscillations in thalamic relay neurons. Biophys J 65:1538-1552.

Destexhe A, Mainen ZF, Sejnowski TJ (1996) Kinetic models of synaptic transmission. In: Methods in neuronal modeling (Koch C, Segev I, eds). Cambridge: MIT Press.

Destexhe A, Contreras D, Sejnowski TJ, Steriade M (1994) A model of spindle rhythmicity in the isolated thalamic reticular nucleus. J Neurophysiol 72:803-818.

Destexhe A, Rudolph M, Fellous JM, Sejnowski TJ (2001) Fluctuating synaptic conductances recreate in vivo-like activity in neocortical neurons. Neuroscience 107:13-24.

Durstewitz D, Seamans JK, Sejnowski TJ (2000) Neurocomputational models of working memory. Nat Neurosci 3(Suppl):1184-1191.

El Boustani S, Pospischil M, Rudolph-Lilith M, Destexhe A (2007) Activated cortical states: experiments, analyses and models. J Physiol Paris 101:99-109.

Fellous JM, Sejnowski TJ (2003) Regulation of persistent activity by background inhibition in an in vitro model of a cortical microcircuit. Cerebral Cortex 13:1232-1241. 
Fellous JM, Rudolph M, Destexhe A, Sejnowski TJ (2003) Synaptic background noise controls the input/output characteristics of single cells in an in vitro model of in vivo activity. Neuroscience 122:811-829.

Gabbott PL, Bacon SJ (1996a) Local circuit neurons in the medial prefrontal cortex (areas 24a,b,c, 25 and 32) in the monkey: I. Cell morphology and morphometrics. J Comp Neurol 364:567-608.

Gabbott PL, Bacon SJ (1996b) Local circuit neurons in the medial prefrontal cortex (areas 24a,b,c, 25 and 32) in the monkey: II. Quantitative areal and laminar distributions. J Comp Neurol 364:609-636.

Gabbott PL, Dickie BG, Vaid RR, Headlam AJ, Bacon SJ (1997) Local-circuit neurones in the medial prefrontal cortex (areas 25, 32 and 24b) in the rat: morphology and quantitative distribution. J Comp Neurol 377:465-499.

Goldman-Rakic PS (1995) Cellular basis of working memory. Neuron 14:477-485.

Goldman MS, Maldonado P, Abbott LF (2002) Redundancy reduction and sustained firing with stochastic depressing synapses. J Neurosci 22:584-591.

Golomb D, Amitai Y (1997) Propagating neuronal discharges in neocortical slices: computational and experimental study. J Neurophysiol 78:1199-1211.

Gonzalez-Burgos G, Barrionuevo G, Lewis DA (2000) Horizontal synaptic connections in monkey prefrontal cortex: an in vitro electrophysiological study. Cereb Cortex 10:82-92.

Graziano MS, Hu XT, Gross CG (1997) Coding the locations of objects in the dark. Science 277:239-241.

Hahn TT, Sakmann B, Mehta MR (2007) Differential responses of hippocampal subfields to cortical up-down states. Proc Natl Acad Sci USA 104:5169-5174.

Haider B, Duque A, Hasenstaub AR, McCormick DA (2006) Neocortical network activity in vivo is generated through a dynamic balance of excitation and inhibition. J Neurosci 26:4535-4545.

Haider B, Duque A, Hasenstaub AR, Yu Y, McCormick DA (2007) Enhancement of visual responsiveness by spontaneous local network activity in vivo. J Neurophysiol 97:4186-4202.

Hasenstaub A, Shu Y, Haider B, Kraushaar U, Duque A, McCormick DA (2005) Inhibitory postsynaptic potentials carry synchronized frequency information in active cortical networks. Neuron 47:423-435.

Henze DA, Gonzalez-Burgos GR, Urban NN, Lewis DA, Barrionuevo G (2000) Dopamine increases excitability of pyramidal neurons in primate prefrontal cortex. J Neurophysiol 84:2799-2809.

Hines ML, Carnevale NT (1997) The NEURON simulation environment. Neural Comput 9:1179-1209.

Hoffman KL, Battaglia FP, Harris K, MacLean JN, Marshall L, Mehta MR (2007) The upshot of up states in the neocortex: from slow oscillations to memory formation. J Neurosci 27:11838-11841.

Holt GR, Softky WR, Koch C, Douglas RJ (1996) Comparison of discharge variability in vitro and in vivo in cat visual cortex neurons. J Neurophysiol 75:1806-1814.

Ikegaya Y, Aaron G, Cossart R, Aronov D, Lampl I, Ferster D, Yuste R (2004) Synfire chains and cortical songs: temporal modules of cortical activity. Science 304:559-564.

Isomura Y, Sirota A, Ozen S, Montgomery S, Mizuseki K, Henze DA, Buzsaki G (2006) Integration and segregation of activity in entorhinal-hippocampal subregions by neocortical slow oscillations. Neuron 52:871-882.

Jahr CE, Stevens CF (1990) A quantitative description of NMDA receptor-channel kinetic behavior. J Neurosci 10:1830-1837.

Krimer LS, Goldman-Rakic PS (2001) Prefrontal microcircuits: membrane properties and excitatory input of local, medium, and wide arbor interneurons. J Neurosci 21:3788-3796.

Lewis BL, O'Donnell P (2000) Ventral tegmental area afferents to the prefrontal cortex maintain membrane potential 'up' states in pyramidal neurons via $\mathrm{D}(1)$ dopamine receptors. Cereb Cortex 10:1168-1175. 
Luczak A, Bartho P, Marguet SL, Buzsaki G, Harris KD (2007) Sequential structure of neocortical spontaneous activity in vivo. Proc Natl Acad Sci USA 104:347-352.

Maass W, Zador AM (1999) Dynamic stochastic synapses as computational units. Neural Comput 11:903-917.

Mao BQ, Hamzei-Sichani F, Aronov D, Froemke RC, Yuste R (2001) Dynamics of spontaneous activity in neocortical slices. Neuron 32:883-898.

McAllister AK, Stevens CF (2000) Nonsaturation of AMPA and NMDA receptors at hippocampal synapses. Proc Natl Acad Sci USA 97:6173-6178.

McCormick DA, Shu Y, Hasenstaub A, Sanchez-Vives M, Badoual M, Bal T (2003) Persistent cortical activity: mechanisms of generation and effects on neuronal excitability. Cereb Cortex 13:1219-1231.

Melchitzky DS, Sesack SR, Pucak ML, Lewis DA (1998) Synaptic targets of pyramidal neurons providing intrinsic horizontal connections in monkey prefrontal cortex. J Comp Neurol 390:211-224.

Mongillo G, Barak O, Tsodyks M (2008) Synaptic theory of working memory. Science 319:1543-1546.

Navratilova Z, Fellous JM (2008) A biophysical model of cortical up and down states: excitatory-inhibitory balance and H-current. In: International School on Neural Nets Dynamic Brain. Erice, Sicily: Springer.

Okun M, Lampl I (2008) Instantaneous correlation of excitation and inhibition during ongoing and sensory-evoked activities. Nat Neurosci 11:535-537.

Paré D, Shink E, Gaudreau H, Destexhe A, Lang EJ (1998) Impact of spontaneous synaptic activity on the resting properties of cat neocortical pyramidal neurons In vivo. J Neurophysiol 79:1450-1460.

Piwkowska Z, Pospischil M, Brette R, Sliwa J, Rudolph-Lilith M, Bal T, Destexhe A (2008) Characterizing synaptic conductance fluctuations in cortical neurons and their influence on spike generation. J Neurosci Methods 169:302-322.

Pratt WE, Mizumori SJ (2001) Neurons in rat medial prefrontal cortex show anticipatory rate changes to predictable differential rewards in a spatial memory task. Behav Brain Res 123:165-183.

Rudolph M, Pospischil M, Timofeev I, Destexhe A (2007) Inhibition determines membrane potential dynamics and controls action potential generation in awake and sleeping cat cortex. J Neurosci 27:5280-5290.

Seamans JK, Durstewitz D, Christie BR, Stevens CF, Sejnowski TJ (2001) Dopamine D1/D5 receptor modulation of excitatory synaptic inputs to layer $\mathrm{V}$ prefrontal cortex neurons. Proc Natl Acad Sci USA 98:301-306.

Shadlen MN, Newsome WT (1998) The variable discharge of cortical neurons: implications for connectivity, computation, and information coding. J Neurosci 18:3870-3896.

Shadlen MN, Newsome WT (2001) Neural basis of a perceptual decision in the parietal cortex (area LIP) of the rhesus monkey. J Neurophysiol 86:1916-1936.

Shi WX, Zheng P, Liang XF, Bunney BS (1997) Characterization of dopamine-induced depolarization of prefrontal cortical neurons. Synapse 26:415-422.

Softky WR, Koch C (1993) The highly irregular firing of cortical cells is inconsistent with temporal integration of random EPSPs. J Neurosci 13:334-350.

Tsodyks M, Kenet T, Grinvald A, Arieli A (1999) Linking spontaneous activity of single cortical neurons and the underlying functional architecture. Science 286:1943-1946.

Uhlenbeck GE, Ornstein LS (1930) On the theory of Brownian motion. Phys Rev 36:823-841.

Wang XJ (2001) Synaptic reverberation underlying mnemonic persistent activity. Trends Neurosci 24:455-463.

Waters J, Helmchen F (2006) Background synaptic activity is sparse in neocortex. J Neurosci 26:8267-8277. 
Watt AJ, van Rossum MC, MacLeod KM, Nelson SB, Turrigiano GG (2000) Activity coregulates quantal AMPA and NMDA currents at neocortical synapses. Neuron 26:659-670.

Yang CR, Seamans JK (1996) Dopamine D1 receptor actions in layers V-VI rat prefrontal cortex neurons in vitro: modulation of dendritic-somatic signal integration. J Neurosci 16:1922-1935.

Zheng P, Zhang XX, Bunney BS, Shi WX (1999) Opposite modulation of cortical N-methylD-aspartate receptor-mediated responses by low and high concentrations of dopamine. Neuroscience 91:527-535. 